\title{
REVISITING ICT ADOPTION THEORIES AND CHARTING A PROGRESSIVE PATH FOR FUTURE ICT ADOPTION RESEARCH IN SMES
}

\author{
Sunday C. Eze \\ Landmark University, Kwara State, Nigeria \\ Sulaimon Olatunji \\ University of Befordshire, UK
}

\section{Vera C. Chinedu-Eze}

Micheal Okpara University of Agriculture, Nigeria

\begin{abstract}
This paper attempts to develop an integrated framework that aims to challenge researchers on a progressive path for future ICT adoption research especially in SMEs. The paper accessed major databases of a number of top IS journals in the field and reviews previous theories used to study ICT adoption, examine the progress made so far, and the limitations of these theories in an attempt to develop a framework, that aims to challenge researchers and aid further contributions in this IS field. The study developed a framework informed by three theories; Structuration theory (ST), Actors Network Theory (ANT) and Adaptive Structuration theory (AST) and argues that using such integrated theory to examine the process of ICT adoption will help to unveil the recursive nature, entities involved and the kind of research approach that may be applied. Hence, for research in this area to be progressive, entities in the framework must be considered amidst other influence. The framework also suggests adoption of ICT will be embraced faster by organizations especially small businesses if the entities involved are committed in conveying the right information thereby supporting SMEs in making adequate decisions. This work provides further insight into ICT adoption framework that may advance future research in the field of ICT adoption, assist SMEs in adopting and implementing ICT overtime. This is relevant given that the complexities associated with the adoption of ICT is becoming worrisome and SMEs have limited knowledge on issues relating to emerging ICTs. The framework may motivate SMEs in understanding diverse actors, factors and social structures affecting ICT adoption better and how to cope with them. The framework serves as an analytical instrument in explaining ICT adoption process and its outcomes characterized by conflicting views.
\end{abstract}

KEYWORDS: ANT, ST, AST, Adoption framework, SMEs, ICT 
Published by European Centre for Research Training and Development UK (www.eajournals.org)

\section{INTRODUCTION}

Huge number of researchers have employed ICT adoption theories in the past. A number of these theories such as resource-based view (RBV), Rogers innovation models (Rogers, 1983; Rogers, 1995), several other additions (Venkatesh et al., 2003), Porter's model (Porter, 1985), others involving in the meta-analysis of these theories(Premkumar, 2003; Adams et al., 1992; Pavlou and Fygenson, 2006) and Intention models (Ajzen and Fishbein, 1980; Davis, 1989) have been advocated which today, are regarded as the most frequently adopted theories by researchers to explain IT adoption decisions in SMEs (Parker and Castleman 2009; Williams et al., 2009). These theories have made vital contributions to information systems research, and to a large extent influenced technology adoption studies for decades; however, they are not only straightforward but also static (Eze et al., 2018) in nature and unable to handle the constant advances in technology and technology adoption (Eze et al., 2014).

Conventional theories of ICT adoption have regularly overlooked the unpredictable nature of ICT adoption, and due to their uncertainty (Venkatesh et al., 2007; Al-Natour and Benbasat, 2009), there is no practical procedure on how it can be adopted overtime (McAfee, 2006; Hirschheim, 2007).Yet these theories regard adoption of technology as easy and straightforward and focus on factors shaping its adoption at a single stage (Eze et al., 2014; Eze et al., 2018). It is argued that the complexity of new ICT adoption are better explored through theories that can explain studies in greater details instead of theories that predict only their levels of outcome. Dominant theories used to assess the values of new technology adoption are becoming less adaptable (Calderia and Ward, 2001; Ray and Ray, 2006) and if continuously applied in studies, will unavoidably hinder the academic debate and limit progressive research in this area (Legris et al., 2001). ICT adoption research need to undergo a change in order to overcome the deterministic conception held by the inventors of these theories. This paper, attempts to develop an integrated framework that may aid progressive path for future research in SMEs by revisiting traditional theories of ICT adoption since studies in this area are the most matured in information systems research (Venkatesh et al., 2003; Brown et al., 2010). The paper is not limited to these theories rather the emphasis here is to reexamine such theories and some social-technical theories, develop of an integrated framework that may proffer a path for future ICT adoption research in SMEs.

\section{LITERATURE REVIEW}

\section{Theory of reasoned action (TRA)}

TRA is well-known, considered a dominant human behavioural theory (Venkatesh et al., 2003), and widely applied to ICT adoption studies. TRA emerged from social psychology due to a weak link associated with the measures of attitude as well as performance of volitional behaviour (Hale et al., 2003; Venkatesh et al., 2003). One of the theories that is related to TRA is the Hierarchy of Effect of High Involvement Behaviour (HEHIB) because it deals with awareness, attitude and behaviour involving an intentionally designated courses of actions (Awa et al., 2010). 
TRA is of the view that intention controls behaviours while subjective norms and attitude shape intentions (Fishbein and Ajzen, 1975). Attitude could be evaluated positively or negatively with the tendency of an act. On the other hand, subjective norm exemplifies the improvement of one 'social status (Rogers, 1995; Rogers, 1983; Venkatesh and Davis, 2000) and the assessment of others about such behaviour(s) (Fishbein and Ajzen, 1975; Pavlou and Fygenson, 2006). According to Taylor and Todd, (1995) suggests that although TRA has contributed extensively in the field of ICT adoption, it has some shortcomings.

First, TRA largely focuses on the behaviours rather than actions that result from such behaviours. The theory is linked to actions that are associated with someone's volitional control (Fishbein and Ajzen, 1975). Therefore, behaviours that are examined by issues that are within an individual control are neglected. The theory according to Sheppard et al (1988) may be difficult to understand when action involves information, resources and skills. This may limit the person performing the act regardless of the fact that an individual intention to act is comparatively high. For instance, if an individual is resolute in adopting new and emerging ICT, it may be that he/she is unable to apply the technology in carrying out his/her duties. Therefore, the capability of an individual or firm to attain its purpose is uncertain despite the efforts of the individual.

Second, TRA laments on the activities or factors associate with a lone behaviour (Benbasat and Barki, 2007; Sheppard et al., 1988). It neglected an option of selecting between different behaviours. Previous studies have revealed that in SME context, immediate and extended family members, networks of friends, and outsiders may have a huge influence on the decisions of the manager. The theory is deterministic, falls within the decision-making school, and actions often selected are rational. TRA may not be suitable to contemporary ICT adoption research because it is incapable to divulge how contradictory forces challenged and are been challenged during the process of technology adoption since the behaviours of individuals regarding the ICT can be anticipated ahead of time if their beliefs, aspirations and attitudes and values are recognised.

\section{Technological acceptance model (TAM)}

TAM is another conventional theory of ICT adoption established to predict the behaviours of ICT adopters (Davis, 1989).TAM has been considered the most powerful and has been extensively adopted in examining technology adoption (Venkatesh et al 2003; Schwarz and Chin, 2007; Benbasat and Barki, 2007; Silva, 2007). TAM was propounded by Davis, (1989) and emerged from TRA. The inventors of the theory used TRA in information systems (IS) because it was discovered by (Ajzen and Fishbein, (1980) that TRA fundamentally examine any behaviour, as such, it would be used to examine the determinants of computer usage (Silva, 2007; Davis, 1989). TAM made TRA simpler which triggered a number of researchers to adopt it in conducting research in ICT adoption, and this has generated contributions in many contexts (Venkatesh et al 2003; Lee, 2003; Benbasat and Barki, 2007).TAM accepts two distinguishing constructs- perceived usefulness and perceive ease of use. These constructs assist researchers 
to discover persons level of IS acceptability (Benbasat and Barki, 2007). Despite TAM contributions in existing body of knowledge, the theory has been accused which lead to some "dysfunctional outcomes" (Venkatesh et al., 2003; Bagozzi, 2007; Benbasat and Barki, 2007). Research studies (Hirschheim, 2007; Silva, 2007) have considered the present condition of TAM and highlighted some of its difficulties in future studies.

According to Benbasat and Barki (2007) TAM has created "illusion of accumulative tradition" which implies that so many studies in the field of ICT adoption have strengthened researchers' understanding on what seems to be the major TAM's relationships. Benbasat and Barki (2007) points out that such understanding has not affected broader areas of implementation and development of technology. Hence, research supported by TAM were unable to address how technology influenced numerous actors during adoption process. This criticism has delayed the advancement of the model mainly in areas related to IT design and execution and has been unsuccessful in producing suitable advice for progressive research in this field(Benbasat and Barki, 2007).

Orlikwski and Gash (1994) argue that effective coordination as well as interaction of different beliefs and behaviours are needed in the development and execution of any technology, and considering technology design and utilisation from an individual has its shortfalls. TRA is limited in predicting or explaining just a single behaviours. The TAM progression to date focusses on opposing model with "techno-centric prediction" (Venkatesh et al 2007; (Benbasat and Barki, 2007). Therefore, research using TAM relied on the technical aspect of IT adoption and overlooked the roles played by human actors.

In addition, TAM is static in nature (Eze et al 2014) and has failed to take into account the evolutionary and /or dynamics in technology adoption in SMEs. "Researchers using TAM concentrated on models that are not dynamic and evaluate all model construct simultaneously in other words, TAM has failed to examine the dynamic interaction between divergent user behaviour that spins between system use" (Benbasat and Barki 2007p. 215). One implication of TAM is that it is useful in explaining attitude of the business managers and their decisions with regard to technology adoption. However, the model is unable to predict decisions of the business frequently (Yu and Tao, 2009). TAM is deterministic as it examines one aspect of the interaction (technology) and abandoned the interaction of human actors. Therefore, it is unable to appropriately describe how varied actors exercise influence which is essential in explaining emerging ICT adoption in SMEs.

\section{Theory of planned behaviour (TPB)}

Theory of Reasoned Action (TRA) was propounded to predict behaviours as well as intentions for volitional as well as actions which can be controlled (Simth and Biddle, 1999). Ajzen (1985) however, is of the view that TRA was not suitable where volitional action are incomplete. Thus, an addition of the theory was proposed and called TPB. TPB was an extension of TRA with perceived behavioural control as an additional variable. TRA and TPB share similar limitation except issues connecting to volition since perceived behaviour takes that into consideration 
(Simth and Biddle, 1999). Perceived behavioural control is associated to perceived ease of displaying the behaviour as well as the expected internal and external resource limitations (Simth and Biddle, 1999; Ajzen, 1991).

Both TPB and TAM have similar route. Both theories are robust in nature and are used in research on issues relating to ethical decision making and other issues, in the same manner, TAM is an important theory for examining behaviours (Venkatesh et al 2007) but they are different when it comes to the types of study and how they are applied in studies. For example, TPB is regarded as a general model for human behaviour, and specific for matters connecting to information guiding decision making (Venkatesh et al. 2007). It considered both subjective norms constructs and perceived behavioural control (as skills, opportunities, and resources for operating systems) to study circumstances where persons or group of persons lack a practical control over the planned behaviour (Awa et al., 2010). Although, IS research have evaluated TPB in the same way TAM has been considered in empirical studies. Ajzen and Fishbein (1980) argue that majority of the research that studies variables connecting to attitude are more prone to adopting TPB framework. Researchers that have used TPB framework have achieved the predictive validity compared to research that replicated studies. Previous studies demonstration consistency with the most recent studies in TAM research (Adams et al 1992; Mathieson, 1991) involving been meta-analysis (Venkatesh et al., 2007).

Although TPB has contributed to IT adoption research, Venkatesh et al (2007) contend that TPB is at is point of maturity, and studies in these areas is now modifying the major constructs and finding substitute constructs to predict behaviour. Bulk of studies that have used TPB neglected the idiosyncratic nature of SMEs and the multifaceted interactions and interrelationships associated with small business managers and other actors - partners, designers and developers, customers, government agencies in the adoption process. TRA, TPB, and TAM assumes that the effect of external actors IT adoption as distinct, instead of intertwined (Ukoha et al 2011). Thus, Silver (2007) argues that academics examining SMEs' adoption of new ICT should consider theories that will explain phenomena in greater details instead of considering deterministic theories like TRA, TAM and TPB. These theories are associated with decision-making school.

\section{Innovation diffusion theory (IDT)}

Innovation Diffusion theory provides an unrelated theoretical lens to that of TRA, TAM and TPB. The theory examines when and how emerging technologies are accepted and/or rejected (Rogers, 1995). With regards to the present evaluation practices, innovation is implemented or rejected and choices are made only if the likely adopters are conscious of the technology innovation and are willing to access its usefulness. IDT is a decision process that seeks to examine the degree associated with the probability rates of adoption which occurs through a channel (a process through which meaning is conveyed from one person to another) within a certain time with the members of a social world (Rogers, 1983; Rogers, 1995). However, 
studies (Simmons et al 2008; Attewell, 1992) argue that the process may not apply to innovations that are multifaceted but rather, those of high involvement behaviour.

A number of studies (Chuang et al 2009; Shiau et al 2009; Rogers, 1995; Attewell, 1992) are of the opinion that the know-how developed through experimentation and empirical learning meaningfully affects the adoption of more multifaceted innovations, as such resource(s) are essential for regular ICT acceptance but however, lacks in SMEs. Roger (1995) suggested the utilization of opinion leaders as well as change agents.

Opinion leadership is defined as the degree to which an individual is willing to influence potential adopters' attitude in a manner that is appropriate. Opinion leaders are normally sustained by both the firm's technical expertise, accessibility, and the acceptance associated with the beliefs and norms of the organisation. Roger, (1995), argues that if businesses are knowledgeable about a change, the opinion leaders tend to innovative in a manner that they contribute to such change as such, they become the major source for fresh ideas. While a change agent is a professional whose responsibility is to influences client innovation decision in a manner that is satisfactory.

The knowledge barriers of the new customers willing to adopt a new innovation may be shaped by the attitudes of the opinion leaders and change agents since their knowledge and experience might be used as a source of information to building expertise knowledge and minimise the perceived risk associated to potential adopters. However, research (Stratopoulos and Lim 2010) demonstrates that organisations are much more knowledgeable and may not essentially depend on the knowledge of the specialist since such specialist can influence them negatively. Also, small businesses regularly built a set of communication network between families, outside, industries and each with its divergent norms, belief and value system may affect adoption. According to Stratopoulos and Lim (2010), such experience and knowledge may greatly influence the organisation.

IDT model has been criticised because it made little or no attempt on the multidimensional social systems of small businesses despite understanding other information and emerging behaviour (Parker and Castleman, 2009). According to Benbasat and Barki (2007) understanding complex nature of social systems of SMEs is a requirement for IT adoption and assist in the design process. Innovation diffusion model neglected how diverse actors that makes technology adoption happen challenge its adoption and utilisation, rather it adopts opinion leaders' for innovation diffusion (Andrade and Urquhart, 2010b).

The model also discovered five innovation characteristics-relative advantages, compatibility, complexity, trialability and observability. These characteristics further disclosures the resemblances of TAM and IDT. These two models are related in one way or the other. For example, relative advantage reveals TAM's perceived usefulness; and complexity relates TAM's perceived ease of use, while some other constructs of Innovation Diffusion model moderate the relationships between the two groups of constructs (Ukoha et al 2011). Karahanna et al (1999) combined TAM and IDT to research on both pre- and post-adoption belief and resolved that real users and possible adopters of ICT deploy so many variables related to 
attitude. Attitudes that have richer innovative features are connected to possible adopters while users attitude, rest on the instrumentality of the confidence of the efficacy of the technology. These shows that the constructs related with each of these models are not of equal importance in examining ICT adoption. TAM and IDT are associated with the decision-making school and they are deterministic in nature and ignored the interaction associated with numerous actors in developing and implementing new ICT. These models are variance in nature and unable describe the multiplicity of adoption of ICT in small businesses (Lawrence, 2010).

\section{Resource-based theory (RBT)}

The resource-based theory describes how organisations can adopt ICT to achieve high performance coupled with competitive advantage (Calderia and Ward, 2001; Ray et al., 2005; Parker and Castleman, 2009). The theory suggests that competitive advantage and high performance would be achieved if organisations only acquire both operating competencies such as human, organizational, physical, as well as customer-value and products that are difficult to imitate. Such assets must be of value, produce returns on investments, and needs a complete learning process, corporate strategies and a change on how things are being done in the organisation (Ravichandran and Lertwongsatien, 2005; Calderia and Ward, 2001).

Caldeira and Ward (2001) is of the view that Resource-based theory include prior experience, firms culture and capabilities which are vital for the success of the organisation, Parker and Casleman (2009) on the other hand, note that organisational resources could be conceptualised as own managers and employee characteristics which has been used by a number of SMEs, and hence, ICT is regarded as one and ICT adoption happens because firms use resources associated with the technology.

One of the major advantages of the theory is that it reveals both tangible and intangible capabilities organisations must acquire to assist in the adoption of ICT infrastructure and applications. RBT is developed to help small business managers acquire knowledge pertaining to competencies that are most valued and permit firms to appreciate how organisational performance can be improved (Calderia and Ward, 2001; Parker and Castleman, 2009). However, it has been argued that this postulation may be suitable only in large organisations since research that have deployed RBT reveals that dynamic organisations do better when they implement technology to assist capabilities and uphold their strategies due to technology competencies developed within the organisation (Parker and Castleman, 2009). This places small businesses in a much challenging situation because they are much more flexible, have restricted resources, family's influence and limited skills (Duan et al 2002). This situation according to Chapman et al (2000) discourage SMEs from engaging in some strategic actions essential to exploit resources in order to meet up with recent capability essential for adopting new technologies.

In addition, previous ICT adoption research have stressed on how actors whether individual, groups, government agencies and other non-profit organisations influence IT adoption (Raza and Standing, 2010). By the same token, Garud and Rappa (1994) claim that the implementation of technology requires an incessant and joint collaboration between technology 
and social world. Therefore, the society is an avenue through which emerging ICT are shaped and replicated. However, RBT failed to adequately account for the external forces such as customers, suppliers as well as non-profit making oriented firms (Parker and Castleman, 2009) such as government agencies despite studies have revealed that external forces play essential roles in shaping ICT adoption, implementation as well as in-house technology competencies.

\section{Michael Porter's models}

The numerous successes credited to Porter' (1980) model is related to the five forces framework which include; degree of competition, the threat of entry, the threat of substitutes, buyer power, and supplier power on business strategy. Michael Porter suggested three general approaches which include low-cost leadership, differentiation, and focus after putting the strategy of a firm in the context of economic forces to help companies in influencing the forces to achieve competitive advantages (Gandhi et al., 2006). The subject of competitive advantage related to Porter's model is linked to issues of firms and competition (Smith and Rupp, 2002). Smith and Rupp, (2002) note that most companies such as the internet ones and conventional companies have engaged in competition that are not healthy and most aspect if the competitive strategies advocated by Porter is violated. They further point out that the way to attain competitive advantages does not involve new technique; rather it entails developing an already established principles of strategic management (Smith and Rupp, 2002). Therefore bridging the gap between ICT strategy and its application is one of the core objectives in building the model.

Ukoha et al (2011) note that the model considers the innovative nature of ICT adoption and seems to be appropriate in technology adoption in SMEs setting. Schubert,( 2007) have used porter's model in small business context to investigate the adoption of Enterprise Resource Planning, while a number of other researchers have applied it in accessing how SMEs use it to position their broad strategies to achieve a considerable competitive advantages. The model describes the risk-taking attitude of a business person in which a business attempts to attain satisfactory strategic positioning.

One major criticism of Porter's model is that usually appropriate to large organisations since their risk-taking activities to economic goals are high. This hampers SMEs in gaining the vital resources to their advantage since they rely on decisions generated from their families, the knowledge acquired by the employees, power as well as trust (Butler et al 2007; Beckinsale et al., 2006). Though Porter's broad strategies looks more robust in developing competitive edge, when combined with (RBV), the theory neglected the number of roles played by actors in matters relating to IT adoption behaviour by small business managers. Instead, the theory's major emphasis was how businesses can engage with the five forces to attain competitive advantage. 


\section{Technology-organisation-environment framework (TOE)}

The TOE framework was established to examine both the characteristics of technology adoption as well as factors shaping technology adoption and its diffusion (Merono-Cerdan, 2008). The framework embraces a comprehensive set of factors that can assist in explaining ICT adoption in organisations. TOE acknowledged three contexts that shapes an organisation's ICT adoption. They are technology, organisation, and environment. Technological context defines the ICT within and outside the organisation; organizational context looks at descriptive measures such as firm's size, its scope, how complex the structure of the management is, human resources; while the environmental context considers the influence of business practice, competition, government and trading partners has on the organisation(Tornatzky and Fleicher, 1990).On the contrary, Rogers(1983) recognised leaders' characteristics, the internal and external business characteristics as a group of adoption predictors (Merono-Cerdan, 2008; Zhu et al 2003).

The leaders' characteristics is associated with the leader's attitude to change; internal features of the firm linked to organisation design which include centralisation, as well as how the external organisation features link to the system's openness and the significance of the technological attributes' which include the qualities of the novelty. Zhu et al (2003) argued that, because the people that make decisions in the organisation are regarded as different internal organisation properties, Rogers's innovation diffusion is related to TOE in terms of adoption predictors, internal features, top management features and external features. Both Roger's model and TOE place much emphasis on the features of a technology which appears to be related to TAM- perceived usefulness and perceived ease of use. The implication of this is that the conditions associated with technology adoption are shaped by the arrangement of the organisation and thus, influenced by the environment of the organisation.

One of the limitation of TOE framework is that it appears to be static and straightforward and emphasises on barriers and drivers of technology adoption. TOE is unable to unveil a complex nature of ICT adoption activities in organisations as well as its dynamics. TOE framework may not be suitable for SMEs because it ignored the complex nature and how flexible small businesses are in their day to day activities. Xu et al (2007), argue that small businesses follow a dynamic path because adoption is not one that is straightforward. According to Rantapuska and Ihanaine (2008), a substantial number of models or theories developed in this area were not meant for ICT adoption in small business context. Though TOE framework is not the same with the previously reviewed models, it is considered as a richer model because it is linked with numerous variables. The model is not appropriate for SMEs because of their idiosyncrasies. Explanatory theories that help explore in greater detail, the implications of the interactions between the social and technical (Dewett and Jones, 2001; Orlikowski and Scott, 2008) integration are needed given that what makes information system unique is the socialtech integration (Bostrom et al., 2009; Hanseth et al 2004). While this call have motivated the proliferation and application of social-technical theories (Silva, 2007), the failure on must academics in the field of ICT adoption research to observe the limitations of these traditional models have contributed in investigating ICT adoption research from either the social 
determinism or technology determinism. A number of studies have argued the combination of structuration theories, Actor-Network Theory (ANT) and its concepts (example, technological frame, inclusion and configuration) to complement each other (Allan, 2004; Hanseth et al, 2004; Lee et al, 1997).

\section{Structuration theory (ST)}

The structuration theory (Giddens, 1979) has been applied in many studies with important emphasis on the social development related to adoption, use and implementation of IT and vital role of the social arrangements. Structuration theories are of the view that structures are only embodied in the mind of human beings or their activities (Bostrom et al., 2009). The theory was established to examine the interaction that exist between the actions of people and social arrangement, which has its basis on the intangible ideas that have no material foundation (Monteiro and Handset, 1996). Structuration theories characterise a condition that leads to the stability or transformation in structure. The transformation in structure is seen as the bases for recreation of social arrangements. Structuration theory emphases on human being legislating structures in a bid to know what they are and as well as using them (Giddens, 1979; Bostrom et al., 2009). Monteiro and Handseth (1996) argue that core component related to structuration theories is lined to a way human activities and the structure are examined and these levels are connected via duality of structure and modality (Giddens, 1979). Duality of structure is highlighted because structures hinder activities, while human activities are seen as a recognised structure. The interaction between the two are achieved via modalities (Monteiro and Handset, 1996). Modalities are linked to interpretive schemes, facility norm and they are associated to both structures and action and have common relations (Monteiro and Handset, 1996).

Studies have recognised the important contributions of Structuration theories, however, using them to examine and understand social-technical entities suffers limitations (Bostrom et al., 2009). Monteiro and Handseth, (1996) argues that these theories were criticised because they were built to examine social systems with a society while the importance of technology as part of the system were neglected. The main emphasis of the theory was majorly on the social structures or how technology can be constructed socially and studied as a social structure enabling or hindering some human actions (Monteiro and Handset, 1996). Structuration theories neglected the roles played by technologies as well as their features in social context. Orlikowski (1992) have sought to further extend the theory and examine the interaction between technology and the social world stressing the importance of duality: that is, "technology is built by people undertaken a given task in a given social context and technology is informally built through the connotation people attach to it as well as the characterises they stressed and use" Orlikowski 1992). Regrettably, how technology influences and are being influenced in the social context are to a large extent ignored because vest number of contributions are linked on "user-centric positions" where the role technology plays is not sufficiently studied if not totally overlooked (Kallinikos, 2004). 


\section{Actor-Network Theory (ANT)}

Actor-Network Theory (ANT) and its applicability (Callon, 1986; Bijker et al, 1989) within IS field looks at the role technology play in the society as well as the process technology shapes and is shaped by the elements in the society continuously (Mahring, 2004). A number of researchers (see Bagozzi, 2007; Venkatesh et al., 2007; Orlikowski and Lacono, 2001) have often deliberated and call for a new theory that will improvement the understanding of the technology (Lee and Oh, 2006), and its implementation in a more robust context (Silva, 2007; Schwarz and Chin, 2007). ANT) was considered as one of the theories. ANT is considered as powerful and can help scholars researchers overcome the poor understanding and implementation of technology (lee and Oh 2006; Lee et al, 1997: Tatnall and Jerzy 2003). Hanseth, et al (2004) have argued that used if researchers are interested in unravelling the emergence, dynamics and use of technology: "commercially driven innovation networks". This theory has been used to understand the dynamic interaction of people and the technology during its design; development and adoption (see Tatnall and Jerzy 2003).

Scholars that propounded and applied ANT initially focused on the sociology of science (Callon, 1986; Latour, 1987; Lee et al 1997). The theory was developed because the early propounded believes technology can be extended to "sociological tool" for analysis (Lee and Oh 2006).For example, the actors associated with the development of the technology are part of the technology development process, and the manner in which the technology is used, their interests, motives, makes it difficult to distinguish the technical from the social. This invariably makes technical characteristics of the producers of the technology social. ANT discards together, the thinking of technology and social determinism (Latour, 1987; Faraj et al 2004; Hanseth et al 2004) for abandoning the ongoing interaction between the society and technology (Hanseth et al., 2004).

According to Lee and Oh (2006) when actors study human as technical, technology is seen as a system in which the inventors inscribe meaning into it. ANT is regarded as an arrangement where the technical and the social world are fused into network. This process is normally through negotiations involving definition of terms, where the key actor tries to enforce roles and descriptions to the other actors (Tatnall and Jerzy, 2003). The theory is concerned with the "creation and maintenance of human and nonhuman element, process of translation and inscription, the creation of black boxes or immutable mobiles and the degree of stability and irreversibility of networks and their elements" (Lee et al 1997:470). Gao, (2005) note that much attention has been gained from the applicability of ANT in numerous studies in ICT adoption and design to extended areas such as "IT development, computer-mediated communication, IT-enabled organisation change infrastructure standards (Allan 2004; Lee and Oh 2006). Hence, ANT offers new ideas that can assist in studying the social and technical aspect of technology as an entity (Lee et al 1997).However, ANT is not without its limitations. And scholars that tend to use this theory must understand its limitations (Lee, et al 1997).

One of the major criticisms of ANT in IT research is treating both human and non-human (technology) as members of the network. However, some of the recent studies using ANT have argued that such criticism is baseless or "unfounded"(see Hanseth, Aanestad, and Berg 
Published by European Centre for Research Training and Development UK (www.eajournals.org)

2004).Although these authors recognised that ANT assumes entirety as an actor-network, however, they argue that this can be same in both human and non-human, and because all networks vary, so do technology and humans also vary with respect to the roles they play in establishments and society as such these differences embrace different actor networks.

In addition, ANT was criticised because it paid little attention to issues of social structures; that is how organisational forces influence the development of social relations and looked at more on how things are being done (Lee et al 2007; Allen 2004). Researchers that are involved in social-technical change are of the same opinion with other social-technical researchers on the belief that although most actors are of the view that interests can be changed; they are of the opinion that actors have some stable structure that are in line with their present practices. Though actors' major objective is to comprehend the changes in the society and technology, it has been argued that such cannot be completely be looked at that way. Allen (2004) argues that structures and organisations can be developed and procedure will stabilise if issues of entrustment and monitoring plans are engaged successfully. Hence organisations are part and are difficult to be disconnected from the plans of the actors (Allen 2004).

\section{Adaptive Structuration Theory (AST)}

AST looks at the relationship between technology, human interactions and the social structures in the organisation. AST sees both the social structures, assets and the processes associated with the technology as well as the organization as the basis for human activities. Social structures triggers social action and it is the social action that produces the structures (Poole and Desancitics 2004).Therefore, structures are seen as rules, resources, and competencies (e.g humans) prearranged in a significant manner as fragments of the organisation. Rules are arrangement people adhere to for example when developing or implementing a technology while resources represent what is been designed and developed by human activities such as technology (Desanctis and Poole, 1994).

Poole and Desancitics (2004) acknowledged seven requirements for active application of AST: identification of structures, description of structures, relationships among structures, appropriation of structures move, contextual impact or influence of structures, Influence of actors and Power dynamics. Here, ANT and ST adopts related position. For instance translation in ANT is realized by displacements that need the implementation of power that may not reach the anticipated outcome. ANT also tries to recognise all the entities associated with the network and how they are related. Arguably structures that are linked to AST may be considered as an essential part of the entity called actor-network and can also represent as actant in ANT (Bostrom et al, 2009). Therefore, the word actors referred as actent in ANT or structures in AST can be regarded as a matter of nomenclature- an act of giving names or matter of classifications (Poole and Desancitics 2004). In line with this Bostrom et al, (2009), note that AST makes structures and human actors as an essential part of an actor-network and accounts for the interaction between technology| (non-human actors) and people (human actors). Hence AST and ANT stressed on the social structures but each at different levels, though, this study 
is of the view that ANT may be bigger compared to structuration approaches as it considered any human and non-human as actors

The difference between AST and ANT is that ANT does not make any prior distinctions of the social world and the technology, on like the AST that considers social structures in a more comprehensive way. For example, when ANT is used in the adoption and use of technology, all the factors inducing adoption weather human and non-human are considered as actors in a network (Tatnall and Jerzy, 2003)

Bostrom et al (2009:24) notes:

"AST allows structures to be separate from the actions or mind of the actors making structures and thus, making structures an objective part of the actors' context allowing them to play an active role in the process along with the actors... as well as the full predictability of IS use in individual, group and organisation. This allows AST to preserve the predictive potential of a deterministic perspective while accounting for interpretative flexibility of the process perspectives".

AST is adopted as a complimentary theory to ANT and ST and may help bridge conceptually, the gap in ANT and ST that by-passes the distinctions between micro and macro level and focused more on micro (individual) level analysis. Studies have suggested the combination of ANT and Structuration theories (see Allan, 2004, Hanseth, Aanestad, and Berg, 2004; Lee et al, 1997). Drawing from these three theories may enable one to adapt both interpretative and predictive approach by adopting mix method approach and triangulating the findings. However, the paper draws on ANT to describe the evolutionary process of technology adoption, actors (including structures) who may be involved in the process of ICT adoption, while AST bridges the gap between the micro and macro level analysis and as a complementary approach to ANT, while ST emphasises more on the social relationships among the human actors at the stages. These approaches allows researchers to look at phenomena in more detailed ways as indicated in the framework.

Drawing on Bijker (1992), ANT, structuration theories, and the key concepts of ANT inscription, framing and stabilisation were deployed as suggested by previous researchers (e.g Bijker, 1992; Hanseth, et al 2004; Lee at al., 1997) in an attempt to develop a framework that may aid a new path for future research in SMEs. Inscription are the features of the technology anticipated which actor tries to initiate as technology (Faraj et al, 2004). This depends on the belief systems of the organisation, previous pattern of use and perception of the role the technology can play (Akrich, 1992; Faraj et al, 2004). Translation looks at how key actors seek the interest of other humanitarian actors to back their ideas of what the technology should represent and have such interest represented at the inscription stage (Tatnall and Jerzy 2003; Gao, 2005; Faraj et al 2004). Translation is regarded as a way innovation is translated, accepted and implemented in an organisation. For this process to be effective there must be an interaction between diverse set of human actors. Framing constitute emerging outcomes as a result of inscribe features and functionalities of the technology (Faraj et al 2004). Stabilisation of technology is a process where the problem associated with the technology has been agreed to 
have been solved by the relevant actors (Bijker et al, 1989). However, it is important to note that businesses process or innovation may evolve thereby causing modification of the technology to suit the current business processes (Bijker et al, 1989).

\section{Identifying entities and developing an integrated framework}

The entities involved in the negotiation process of ICT adoption should not be taken for granted if a new path for future ICT adoption is to be encouraged. The new path involves looking at adoption of ICT from an emerging perspective. In doing so, researchers must consider who should be involved; human, non-human actors as well as social structure or relations influencing the network. Dynamic process perspective can be viewed as a strategy involving a system of relations ( $\mathrm{Ng}$-Kruelle et al 2005) among the actors in a network that shape and are being shaped by the technology leading to definition and redefinition of the technology.

Drawing extensively on Eze et al 2014 and Eze and Chinedu-Eze (2018) research finding, a number of human and non- human actors have been identified which may be studied partly or in whole when investigating ICT adoption from emergent perspective. When studying ICT adoption in SMEs, recognising the key actor as the SME managers is vital and most often because of the characteristics of SMEs, as well as their social formation and decision to adopt, are mostly rest on the managers, especially those that started with a single business idea. An external force like customers pay vital role in generating ideas and facilitates the adoption of new applications because they are the major reasons SMEs are in business. Developers, vendor, IT staff are crucial with regards to making decisions on how new technology are designed and developed especially if SMEs cannot afford to design and develop the technology inhouse. The general public such as government and its agencies, the social structures as well as the society that are not part of the developers or consumers but can influence the entire process in terms of maintaining development standards. ICT represents all applications such as computers, mobile applications, software, and other communication infrastructures. 


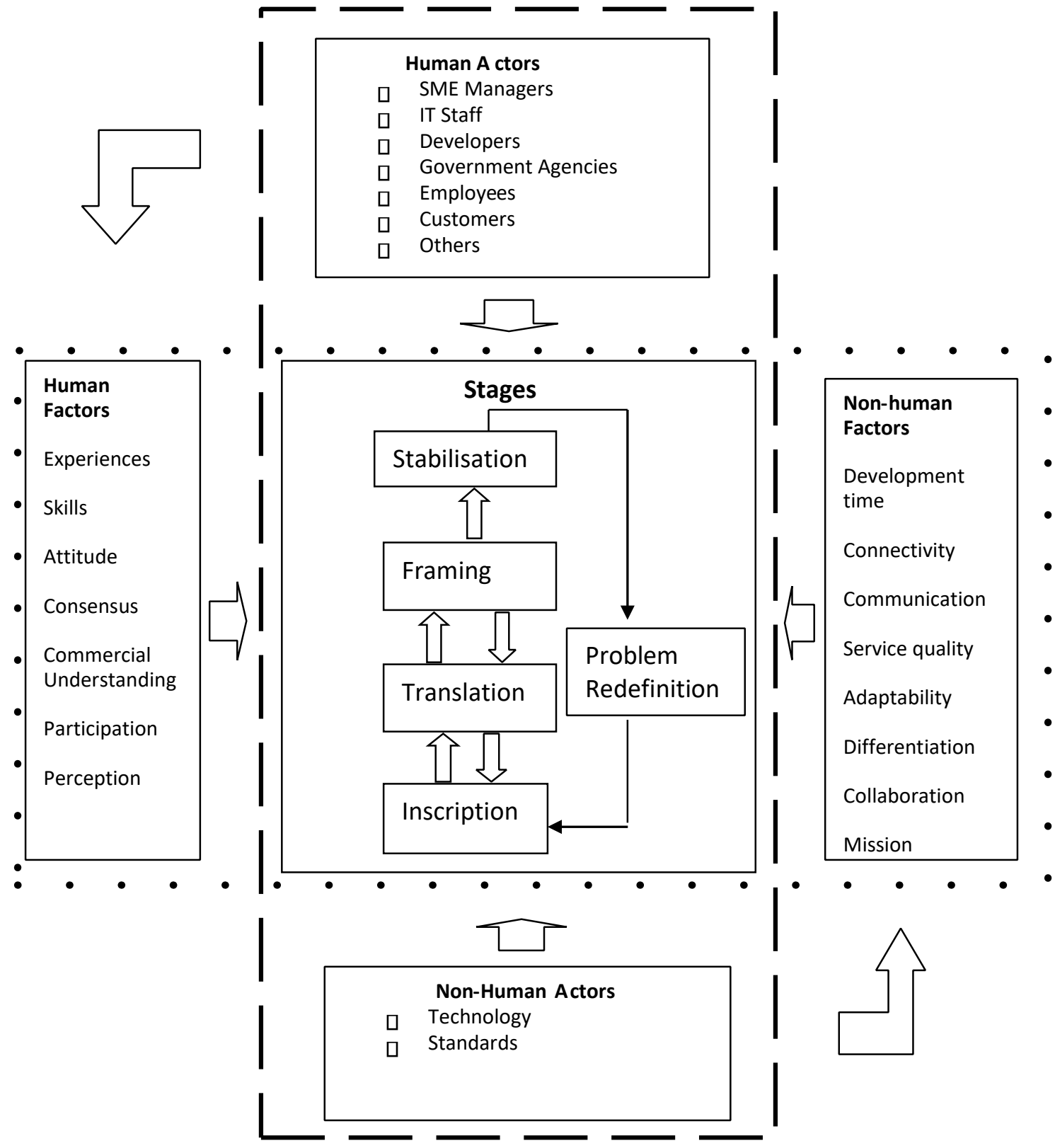

Figure 1: ICT adoption Framework is about here

\begin{abstract}
ANALYSIS
Evidence from the literature review suggests that huge number of models/theories have been developed from linear models to conventional adoption theories of ICT adoption. Arguably these theories have provided a great deal of insights on adoption studies however, one major challenges confronting these theories are unable reveal the complexities involved in new technology adoption as well as in SMEs. Both the conventional and social-tech theories if deployed alone are unable to explore the multiple actors, with each, having its opposing norms,
\end{abstract}


interests, and value systems (Parker and Castleman, 2009). While linear models and the adoption ladder have been criticised for over-simplifying on complex matters related with SMEs, conventional theories are associated with decision-making school as they share similar features because of the determinist conception entrenched in the applications (Barrett et al., 2006). These theories are of the view that factors external to an individual deeply influence the firms outcome while actors' decisions are regarded irrelevant (Bostrom et al., 2009). These theories are problematic because they have constantly neglected the roles played by human agency despite research have been conducted within the social context where actors control agency during the process of change. (Bostrom et al 2009).

Evidence from the Literature review also suggested that the emergent perspective (that is where human and the technology emerge from unpredictable and complex social interaction) is capable to reveal the issues (Markus and Robey, 1998). This position offers a new prospects for academics and scholars to challenge the fundamental philosophies and norms which most conventional theories of ICT adoption were developed, however, this area is still silent in literature (Markus and Robey, 1998). In an attempt to recognize the actors involved in ICT adoption which studies have started seeing as the contemporary organisations norms (Orlikowski and Scott, 2008) remains essential for progressive research in this field. According to Markus and Robey, (1998) this perspective sees technology as an essential part of the complex process through which firms accomplish tasks, and emphases on the dynamic relations between people, structures, and technology overtime(Orlikowski and Scott, 2008). Therefore, studies should not limit their research to either the technical or the social rather, it is valuable to study their dynamic interactions.

In support of the above, the framework demonstrates that social-technical phenomena considers the mutual understanding of various actors that engage in the negotiation process and influence the development of new technology. The paper reveals that technology and the social development of the technology and its adoption must be studied in a bid to achieve both the economic, social and the technology impact. Focusing on the analysis of the social-technical aspect of technology adoption, a number of questions emerged in relation to the holistic development of technology and its adoption which studies must address using this framework: This included; how do new technology originate in small businesses? Who are the various actors that are involved in the initiation, interpretation and development of the technology? How new technologies are institutionalised and what are the unexpected change that leads to redefinition of interest. The integrated framework demonstrates ever continuing struggles for the creation, adoption and adaptation of technology and identifies possible factors that might affect the process since the way actors interpret their interests entrenched in the technology is flexible in the same manner human actors' interests are flexible. Therefore, to capture the flexibility, adaptableness and predictive nature, entail numerous representation including both the social and technical aspect of both human and non-human (Gao, 2005) must be studied along the adoption process to be able to determine at what stage(s) these factors influence the process. 
Published by European Centre for Research Training and Development UK (www.eajournals.org)

\section{CONTRIBUTIONS}

The development and adoption of ICTs have been studied in different perspectives and differs according to the context. Studies in this area have been consistently refined because technologies are unstable and often experience changes such as in the case of internet applications (Orlikowski, 2002). This implies that the evolution of technology, its development and adoption process is not a "one-time decision but a continuous process of living with the evolving innovation" $\mathrm{Ng}$-Kruelle et al (2005) and involves a continuous deliberation of actors at every stage. The conventional theories of ICT adoption centres on a limited number of socialtechnical perspectives which either address the technical aspect with the social aspect in isolation or predict empirical findings in a very narrow way. The paper demonstrates that improvement in productivity and easier work translation are gained when social-technical theories (ST ANT and AST) are integrated and use in ICT adoption research. While this paper recognizes the challenges of integrating the findings into a large integrated theory that addresses the dynamics of social -tech approach, the integrated framework gives a better understanding of both elements of social and the technical which may be involved in successful ICT adoption in SMEs, bridges the gap of micro-level analysis at but individual and organisational level and offers opportunity to use more exploratory approach.

Although SMEs are willing to participate in developing and adopting new solutions to streamline their processes, they still function in a dynamic, volatile and complex business environment and much of the studies conducted in this area have focused on large organisations while accounting only $8.6 \%$ in SMEs (Williams et al 2009). Arguably, this might be due to the inappropriate theories that may have been applied in SMEs in the past. Therefore, this paper challenges current ICT adoption researcher to be much more proactive by adopting an integrated and dynamic framework that will unravel continuous challenging facing small businesses in adopting and implementing new technologies.

In applying the framework researcher much bear in mind that effective flow of information is essential among the actors to ensure that interest and views in the network are adequately understood. If accurate and adequate information are conveyed among actors in the network, during the negotiation process, misalignment of interest and time will be reduced compared to when inadequate information are disseminated. The implications are that SMEs will be willing to challenge and in a long run be convinced, committed and willing to seeing that new ICTs are implemented with less resistance. Also, the business processes and operations of the business will be much better and streamlined quickly.

Finally, a number of studies (; Galliers and Land, 1987; Williams et al., 2009; Orlikowski and Baroudi, 1991; Choudrie and Dwivedi, 2005) have investigated approaches use in ICT adoption research. The findings reveals that majority used quantitative method (Williams et al., 2009). Survey method is still the most dominant approach while other methods such as longitudinal, grounded theory approach, interviews, mixed methods, mathematical model, secondary data analysis, action research are hardly used(Williams et al., 2009). Although quantitative approaches has contributed to adoption research, however, these approach consider ICT adoption research as predictable and straightforward and emphasises on the factors affecting 
adoption at one decision point. This method if constantly use will unavoidably obstruct the academic debate and limit the progressive path for future research in this field. The framework demonstrate that ICT adoption research could be studied from an alternative and more explanatory and integrated framework that provide a m more insights as to how research in SMEs can be continually studied.

Also why the paper emphasised on SMEs, extent studies should not limit their research using this framework for just SMEs instead, further research may be need to use the framework in large organisation by using all the entities in the framework to unravel such questions as how do new technology originate in small businesses? Who are the various actors that are involved in the initiation, interpretation and development of the technology? Explore how new technologies are institutionalised and what are the unexpected change that leads to redefinition of interest. In addition, the potential factors have been grouped under the following headingshuman and non-human factors. Human factors are linked to human actors, while non-human are associated to non-human actors. Though this factors are not exclusive empirical work using a longitudinal approach will be necessary to examine the factors, actors as well as their roles in every stage of the adoption process in order to understand how they shape the process and whether such roles, factors (human and non-human) vary at each stage.

\section{CONCLUSION}

The way ICT is adopted in organisations today is changing. This calls for a new theoretical dimension that will help advance research in this area. With the fast advancements in technology, conventional theories such as Technology Acceptance Model (TAM) and its extended models, Rogers Diffusion of Innovation (DOI) theory and other prominent theories of adoption have dominated the ICTs adoption studies in the past however, they are mainly deterministic, static and do not reflect the dynamics and the level of complexities involved in ICT adoption. They totally ignored the notion that technology adoption is an evolving, continuing and iterative process. As such a framework was developed on the belief that if researcher continue to apply these theories, it may be difficult to unravel some of the present and future issues facing SMEs in adopting and implementing new technologies.

ST, ANT and AST were integrated on the account that none of these theories if used may fully demonstrate the dynamic and volatile nature of ICT adoption. Although, ST is dynamic in nature and appropriate in explaining technology adaptation that is aimed at introducing new ICT (Faraj et al 2004), the theory leads to poor conceptualization of technology (Hanseth et al 2004) because it looks at ICT adoption in a narrow manner and disregards the fact that structures are entrenched by developers during technology development (Bostrom et al 2009). in addition, ANT was critiqued because the theory looked at how institutional actors influences the social interaction process in a limited way and highlights more on how things are being done (Lee et al 2007; Allen 2004). The AST was adopted as a complementary theory to conceptually bridge the gap in ANT and ST that by-passes the distinctions between micro 
and macro level and focused more on micro (individual) level analysis. This lead to the development of an integrated framework that may explain phenomenon in greater details.

\section{REFERENCES}

Adams, D. A., Nelson, R. R. \& Todd, P. A. (1992). Perceived usefulness, ease of use, and usage of information technology: A replication. MIS Quarterly, 16(2), 227-247.

Ajzen (1991). The theory of planned behaviour. Organizational behaviour and human decision processes, 50, 179- 211.

Ajzen, I. (1985). From intentions to actions: A theory of planned behaviour In KUHL, J. \& BECKMANN, J. (eds.) Action control: From cognition to behaviour. Berlin: Springer.

Ajzen, I. \& Fishbein, M. (eds.) (1980). Understanding attitudes and predicting social behaviour New Jersey: Prentice-Hall.

Andrade, A. D. \& Urquhart, C. (2010). The affordances of actor-network theory in ICT for development research. Information Technology and People, 23(4), 352-374.

Al-Natour, S. \& Benbasat, I. (2009). The adoption and IT artefacts: A new interaction-centric model for the study of user artefact relationships. Journal of Association for Information Systems, 10(9), 661-685.

Akrich, M., Callon, M. \& Latour, B. (2002a). The key to success in innovation part 1: The art of interessement. International Journal of Innovation Management 6(2), 187-206.

Akrich, M., Callon, M. \& Latour, B. (2002b). The key to success in innovation Part 11: The art of choosing good spokespersons. International Journal of Innovation Management, 6(2), 207-225.

Attewell, P. (1992). Technology diffusion and organizational learning: The case of business computing. Organization Science, 3 (1), 1-19.

Awa, H. O., Nwibere, B. M. \& Inyang, B. J. (2010). The uptake of electronic commerce by SMEs: A mete theoretical framework expanding the determining constructs of TAM and TOE framework. Journal of Global Business and Technology 6(1), 1-27.

Bagozzi, R. P. (2007). The legacy of the technology acceptance model and a proposal for a paradigm shift. Journal of the Association for Information Systems, 8(4), 244-254.

Beckinsale, M., Levy, M. \& Powell, P. (2006). Exploring internet adoption drivers in SMEs Electronic Markets, 16(4), 361-370.

Benbasat, I. \& Barki, H. (2007). Quo Vadis, TAM? Journal of the Association for Information Systems, (8), 211-218.

Bijker, W. E., Hughes, T. P. \& Pinch, T. (eds.) (1989). The social construction of technology systems: New direction in the sociology and history of technology, USA: Maple -Vail, Inc.

Bijker, W. E. \& Law, J. (eds.) (1992). Shaping technology building society: Studies in social technical change, Cambridge, Massachusetts: The MIT Press.

Bostrom, R. P., Gupta, S. \& Thomas, D. (2009). A meta-theory for understanding information systems within social technical systems. Journal of Management information Systems, 26(1), 17-47.

Brown, D. H. \& Lockett, N. (2004). Potential of critical e-applications for engaging SMEs in e-business: A provider perspective. European Journal of Information Systems, 13, 21 34. 
Brown, S. A., Dennis, A. R. \& Venkatesh, V. (2010). Predicting collaboration technology use: Integrating technology adoption and collaboration research. Journal of Management Information Systems, 27(2), 9-53.

Butler, A., Reed, M. \& Grice, P. L. (2007). Vocational training: Trust, talk, and knowledge transfer in small businesses. Journal of Small Business and Enterprise Development, 14(2), 280-293.

Callon, M. (1986). Some elements of a sociology of translation: domestication of the scallops and the fishermen of the Brieuc Bay. In: LAW J. (ed.) Power, action and belief: A new sociology of knowledge? London, Routledge.

Callon, M. (1991). Techno-economic networks and irreversibility. In: LAW, J. (ed.) A sociology of monster: Essays on power, technology and domination. London: Routledge.

Callon, M. (1999). Actor-network theory-The market test. In: LAW, J. \& HASSARD, J. (eds.) Actor network theory and after. Oxford: Blackwell Publishing.

Callon, M. \& Latour, B. (1981). Unscrewing the big leviathan: How actors macro -structures reality and how sociologists help them to do so. In: KCETINA, K. \& CICOUREL, A. V. (eds.) Advances in social theory and methodology: toward an integration of macro and macro-sociology. London: Routledge

Calderia, M. M. \& Ward, J. M. (2001). Using resource -based theory to Interpret the successful adoption and use of information systems and technology in manufacturing small and medium sized enterprises. Glonal co-operation in the New Millennium. The 9th European Conference on Information Systems. Bled, Slovenia.

Chuang, T., Nakatani, K. \& Zhou, D. (2009). An exploratory study of the extent of information technology adoption in SMEs: An application of upper echelon theory. Journal of Enterprise Information Management 22(1/2), 183-196.

Chapman, P., M.James-Moore, Szczygiel, M. \& Thompson, D. (2000). Building Internet capabilities in SMEs. Logistics Information Management, 13(6), 353-360.

Davis, F. D. (1989). Perceived usefulness, perceived ease of use and acceptance of information technology. MIS Quarterly, 3(3), 319-340.

Duan, Y., Mullins, R., Hamblin, D., S Stanek, H Sroka, Machado, V. \& Araujo, J. (2002). Addressing ICTs skills challenges in SMEs: insights from three country investigations. Journal of European Industrial Training, 26(9), 430-441

Dewett, T. \& Jones, G. R. (2001). The role of information technology in the organisation: A review, model and assessment. Journal of Management 21,109-118.

Desanctics, G. \& Poole, M. S. (1994). Capturing the complexity in advanced technology use: Adaptive Structuration Theory. Organisation and Science 5(2), 121-147.

Eze S.,Duan Y\& Chin H.(2014) Examining Emerging ICT's Adoption in SMEs from a dynamic Process Approach. Information Technology and People 27 (1), 63-82

Faraj, S., Kwon, D. \& Watts, S. (2004). Contested artifact: technological sense making, actor networks and the shaping of the web browser. Journal of Information, Technology and People, 17(2), 186-209.

Fishbein, M. \& Ajzen, I. (1975). Belief, attitude, intention, and behaviour: An introduction to theory and research. Reading Addison-Wesley.

Gandhi, N. M. D., Selladurai, V. \& Santhi, P. (2006). Unsustainable development: A conceptual model. Management of Environmental Quality: An International Journal, 17(6), 654-672. 
Garud, R. \& Rappa, M. A. (1994). A social -cognitive model of technology evolution: the case of cochlear implants. Organisation Science, 5(3), 344-362.

Gao, P. (2005). Using actor-network theory to analysis strategy formation. Information Systems Journal, 15(15), 225-275.

Giddens, A. (ed.) (1979). Central problems in social theory: Action, structure and contradiction in social analysis, Berkeley: University of California Press.

Hale, J. L., Householder, B. J. \& Lgreene, K. (2003). The theory of reasoned action. In: DILLARD, J. P. \& PFAU, M. (eds.) The persuasion handbook: Developments in theory and practice Sage. Thousand Oaks.

Hirschheim, R. (2007). Introduction to the special issue on "Qua Vadis TAM- Issues and reflections on technology acceptance research. Journal of the Association for Information Systems, 8(4), 203-205.

Karahanna, E., Straub, D. W. \& Chervany, N. L. (1999). Information technology adoption across time: a cross-sectional comparison of pre-adoption and post adoption beliefs. MIS Quarterly, 23(2), 183-213.

Latour, B. (1987). Science in action Cambridge, Massachusetts, Harvard University Press.

Latour, B. (ed.) (1999). On Recalling ANT, Oxford: Balckwell Publishing

Latour, B. (2005). Reassembling the social: An introduction to actor-network-theory Oxford, Oxford University Press.

Latour, B. (2011). Network, society, spheres: Reflections of an actor -network theorist. International Journal of Communication, 5,796-810.

Lawrence, J. (2010). The factors that influence adoption and usage decision in SMEs: E

Lawrence, J. (2010). The factors that influence adoption and usage decision in SMEs: Evaluating interpretive case study research in information systems. The Electronic Journal of Business Research Methods, 8(1), 51-62.

Lee, Y. (2003). The technology acceptance model: Past, present and future, Communication of the Association of Information Systems, 12(50), 752-780.

Lee, H. \& Oh, S. (2006). A standards war waged by a developing country: Understanding international standard setting from the actor -network perspective. Strategic Information Systems, 15,177-195.

Legris p., Ingham J., Collerette p. (2001) Why do people use information technology? A critical review of the technology acceptance model. Information and Management 40(191-204)

Markus, M. L. \& Robey, D. (1998). Information technology and organisational change: causal structure in theory and research. Management Science, 34(5), 583-598.

Mahring, M., Holmstrom, J., Keil, M. \& Montealegre, R. (2004). Trojan actor networks and swift translation: bring actor-network theory to project escalation studies. Information Technology and People, 17(2), 210-238.

Merono-Cerdan, A. L. (2008). Groupwise users and influence on performance in SMEs. Journal of Computer Information Systems, 48(4), 87-96.

Monteiro, E. \& Handset, O. (1996). Social shaping of information infrastructure: On being specific about the technology. In: ORLIKOWSKI, W. J., WALSHAM, J., JONES, M. R. \& DEGRESS, J. I. (eds.) Information Technology and Change in Organisational Work. London. Chapman and Hall. 
Hanseth, O., Aanestad, M. \& Berg, M. (2004). Guest editor' Introduction: Actor network theory and information systems. What's so special?. Information, Technology and People, 17(2), 116-123.

Orlikowski, W. J. (1992). The duality of technology: Rethinking the concept of technology in the organisations. Organisation Science, 11(4), 404-428.

Orlikowski, W. J. \& Baroudi, J. J. (1991). Studying information technology in organisations: research approaches and assumptions. Information Systems Research, 2(1), 1-28.

Orlikowski, W. J. \& Gash, D. C. (1994). Technological frame: Making sense of information technology in organisation. ACM Transactions on Information Systems, 12(2), 174207.

Orlikowski, W. J. \& Lacono, C. S. (2001). Research commentary: Desperate seeking the IT in IT research-a call to theorizing the IT artefact. Information Systems Research, 12(2), 121-134.

Orlikowski, W. J. \& Scott, S. V. (2008). Sociomateriality: Challenging the separation of technology London: London School of Economics and Political Science.

Parker, C. M. \& Castleman, T. (2009). Small firm e-business adoption: a critical analysis of theory. Journal of Enterprise Information Management, 22(1/2), 167-182.

Pavlou, P. A. \& Fygenson, M. (2006). Understanding and predicting electronic commerce adoption: an extension of the Theory of Planned Behaviour. MIS Quarterly, 30(1), 115143.

Porter, M. \& Millar, V. (1985). How information gives you competitive advantage. Harvard Business Review, 63(4), 149-160.

Porter, M. E. (1985). Competitive advantage: Techniques for analysing industries and competitors New York: The Free Press.

Premkumar, G. (2003). A meta-analysis of research on information technology implementation in small business. Journal of Organisational Computing 13(2), 91-121.

Rantapuska, T. \& Ihanainen, O. (2008). Knowldge use in ICT investment decision making of SMEs. Journal of Enterprise Information Management, 21(6), 585-596.

Ray, A. W. \& Ray, J. J. (2006). Strategic benefit to SMEs from third party web services: An action research analysis. Journal of Strategic Information Systems, 15,273-291.

Ray, G., Muhanna, W. A. \& Barney, J. B. (2005). Information technology and the performance of customer service process: A resource based analysis. MIS Quarterly, 29(4), 625-652.

Ravichandran, T. \& Lertwongsatien, C. (2005). Effect of information system resources and capabilities on firm performance: A resource-based perspective. Journal of Management Information Systems, 21(4), 237-276.

Raza, S. A. \& Standing, C. (2010). Towards a systematic model on information systems adoption using critical systems thinking Journal of Systems and Information Technology, 12(3), 196-209.

Rogers, E. (ed.) (1983). Diffusion of innovation New, New York: Free Press.

Rogers, E. (ed.) (1995). Diffusion of innovation, New York: Free Press.

Schwarz, A. \& Chin, W. (2007). Looking forward: Toward an understanding of the nature and definition of IT acceptance. Journal of the Association for Information Systems, 8(4), 230-243.

Schubert, P. (2007). Business software as a facilitator for business process excellence: Experiences from case studies. Electronic Markets, 17(3), 187-198. 
Sheppard, B. H., Hartwick, J. \& Warshaw, P. R. (1988). The theory of reason action: A Meta -analysis of past research with recommendations for modifications and future research. Journal of Consumer Research, 15(325-343).

Shiau, W., Hsu, P. \& Wang, J. (2009). Development of measures to assess the ERP adoption of small and medium enterprises. Journal of Enterprise Information Management 22(1/2), 99-118.

Silva, L. (2007). Post -positivist review of technology acceptance model. Journal of the Association for Information Systems, 8(4), 255-266.

Simmons, G., Armstrong, G. \& Durkin, M. (2008). A conceptualization of the determinants of small business website adoption: Setting the research agenda. International Small Business Journal 26(3), 351-389.

Simth, R. A. \& Biddle, S. J. H. (1999). Attitudes and exercise adherence: test of the theories of reasoned action and planned behaviour. Journal of Sports Sciences, 17(4), 269-281.

Stratopoulos, T. C. \& Lim, J. (2010). Innovation persistence: An Oxymoron. Communication of the ACM, 53(5), 142-146.

Tatnll, A. \& Jerzy, L. (2003). The internet e-commerce and older people: An actor-network approach to researching reasons for adoption and use. Logistic Information Management, 16(1), 56-63.

Taylor, S. \& Todd, P. (1995). Understanding information technology usage: a test of competing models. Information Systems Research, 6(2), 144-174.

Tornatzky, L. \& Fleische, M. (1990). The Process of Technology Innovation, Lexington, M.A., Lexington Books.

Williams, M., Dwivedi, Y. K., Lal, B. \& Schwarz, A. (2009). Contemporary trends and issues in IT adoption and diffusion research .Journal of Information Technology 24, 1-10.

Venkatesh, V., Morris, M. G., Davis, G. B. \& Davis, F. D. (2003). User acceptance of information technology: Toward a unified view. MIS Quarterly, 27(3), 425-478.

Venkatesh, V., Davis, F. \& Morris, M. G. (2007). Dead or alive? The development trajectory and future adoption research. Journal of Association for Information Systems 8(4), 267286.

Venkatesh, V. \& Davis., F. (2000). A theoretical extension of the technology acceptance model: four longitudinal field studies. Management Science, 46(2), 186-204.

Xu, M., Rohatgi, R. \& Duan, Y. (2007). E business adoption in SMEs: Some preliminary findings from electronic component industry. International Journal of E-Business Research 3(1), 74-90.

Yu, C. \& Tao, Y. (2009). Understanding business level innovation technology adoption. Technovation, 29, 92-109.

Zhu, K., Kraemer, K. \& Xu, S. (2003). Electronic business adoption by Europe firms: A crosscountry assessment of the facilitators and inhibitors. European Journal of Information systems, 12,251-256. 